\title{
Field Validation of Erosion Hazard Zones for Small Scale Assessment using GIS
}

\author{
G.R.N. Karunatilaka and N.T.S. Wijesekera
}

\begin{abstract}
Soil erosion is one of the most serious environmental problem of agricultural based developing countries since it remove soils rich in nutrients, increase natural level of sedimentation in rivers and other water bodies and causes flood and water quality problems. The final results are the reduction of the productivity of land, which can lead to increase in expenditure in fertilizers to maintain yields and reduction in capacity of rivers increasing the risk of flooding, blocking of irrigation canals and shortening the design life of reservoirs. Soil erosion assessment for watershed management is one of the major concerns because, in reality, it is not possible to conserve all areas under the threat of erosion due to financial constrains. Soil loss rate or erosion rate estimation for land parcels is of utmost importance to the effort of soil conservation work. The most common method in the world to identify land parcels which are severely eroded is Universal Soil Loss Equation (USLE). It predicts the longterm average annual rate of erosion. However, the factors in this equation require field validation prior to their application for a particular region. This study was carried out for a relatively small area and this paper describes the key issues, methodology and recommendations for the process of soil erosion assessment of such an area. Erosion hazard in a watershed has spatially varying characteristics. Hence, the use of a computer tool, which can handle spatial data, is important. Geographic Information System (GIS) provides an easy solution for such spatial assessments for effective watershed management.
\end{abstract}

\section{Introduction}

Land resource is primarily important for all developing countries, particularly in countries like Sri Lanka, where the majority of the people are either directly or indirectly dependent on agriculture for their livelihood. Hence, soil erosion is one of the most serious environmental problems of agricultural based developing countries since it remove soils rich in nutrients, increase the natural level of sedimentation in rivers and other water bodies and causes flood and water quality problems. Soil erosion assessment for watershed management is one of the major concerns because, in reality, it is not possible to conserve all areas under the threat of erosion due to financial constrains. Soil loss rate or erosion rate estimation for land parcels is of utmost importance to the effort of soil conservation work. Erosion hazard in a watershed has spatially varying characteristics. Hence, the use of a computer tool, which can handle spatial data, is important. Geographic Information System (GIS) provides an easy solution for such spatial assessments for effective watershed management. GIS is becoming a popular tool when seeking solutions to issues of these kinds, which are spread over large spatial extents. The most common method for soil erosion assessment in the world is
Universal Soil Loss Equation (USLE). Parameters in this equation were tested for United States conditions but most other own countries have identified parameters suitable for their countries. There fore, before using this equation for a particular area, it is necessary to calibrate it for that region. The objective of this project is the development of a soil erosion model and verification of that model for a particular area.

\section{Study location}

The selected site area is located in Katubedda, Moratuwa in the Southern part of the Colombo district of Sri Lanka (fig. 1). It covers approximately 25 ha and is in the locality of the University of Moratuwa. The area is in the wet zone of Sri Lanka and experiences two rainy seasons namely Maha and Yala.

The mean annual rainfall of the area during the last ten years is $2485 \mathrm{~mm}$ according to the data available in the Meteorology Department. The

Eng. (Ms.) G. R. N. Karunatilaka. BSt: Eng. M. Phil., AMIESL Presently. Civil Engineer. National Transport Commission.

Eng. (Prof.) N. T. S. Wijesekera - BSc Eng. (Hons) Sri Lanka. PG Dip (Moranwwa), M. Eng. (Trowo). D. Eng. (Tokyor). C. Eng.. MICE (London), FIE (Sri Lanka). Professor of Civil Engincering and the Chriman of the International Center for Guoinformatics Applications and Training at University of Moratuwa. 


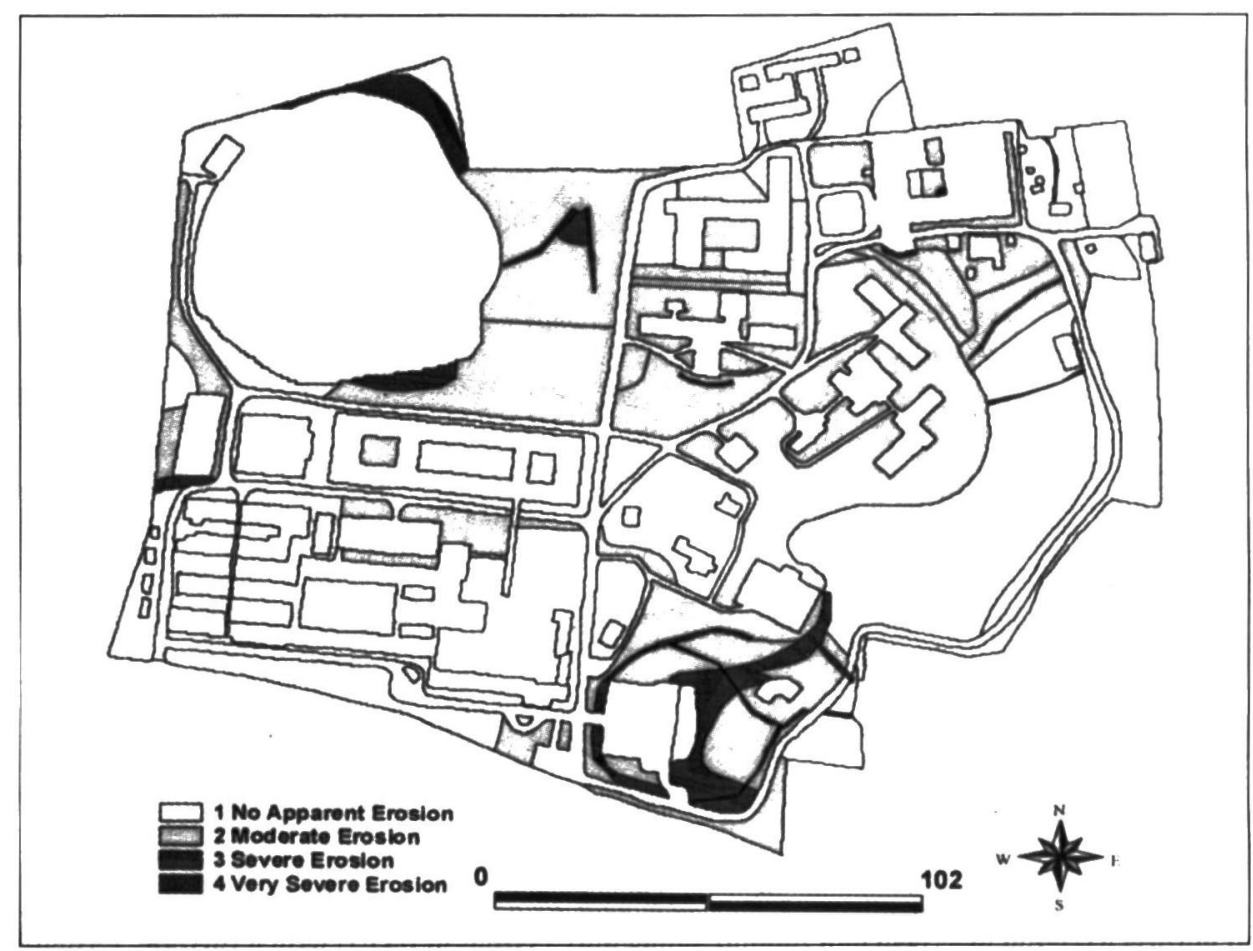

Figure 1: Research area (UOM premises), rain gauge stations and degree of observed erosion in the area.

area has a flat region as well as hilly terrain with the elevation ranging from $0 \mathrm{~m}$ to $23 \mathrm{~m}$ above mean sea level. The topographical map shows that the eastern part of the area has hilly terrain while the North Western part of the area is flat. The available soil maps indicate that the area has one soil type named as Red Yellow Podzolic.

\section{Data collection}

A field data collection was done to collect details of land use, soil properties, rainfall, conservation practice used in the area and existing erosion levels. Land use patterns were marked in the map in a scale of 1: 1200 using a pre-coding system identified during the reconnaissance survey. Land cover distribution in the area is given in Table 1.

Table 1: Land use patterns and extent in the area

\begin{tabular}{|ll|c|c|}
\hline \multicolumn{1}{|c|}{ Land use } & \%Area & Area $(\mathrm{m} 2)$ \\
\hline 1. & Building & 17.54 & 43850 \\
2. & Forest & 11.73 & 29325 \\
3. & Scrub cover & 5.23 & 13075 \\
4. & Garden & 42.2 & 105500 \\
5. & Bare space & 1.43 & 3575 \\
6. & Grassed & 13.36 & 33400 \\
7. & Paved (Roads) & 8.51 & 21275 \\
\hline
\end{tabular}

The soil type in the area was identified using collected data during field surveys and Moorman (1966) guidelines. This was the same type as identified in the national atlas for the area. Existing erosion levels were classified into four types using data collected in the field, the method mentioned in FAO soil conservation guideline and Morgan (1995). A quantitative scheme was prepared to differentiate each erosion class easily and is as shown in Table 2 . The method of assessment described by Morgon (1995) was difficult without a specific description of erosion levels and hence a coding leading to a quantitative assessment was used. (Karunatilaka and Wijesekera 2001)

Daily rainfall data was collected using three rain gauge stations during the year 2001 to prepare the methodology to find out annual rainfall for the last 20 years within the area comparative to the Ratmalana rain gauge station which is the nearest rain gauge station to the area.

Daily rainfall during the year 2001, annual rainfall and rainfall intensity from 1981 to 2001 were collected from the Meteorological Department to compare the rainfall values recovered within the area and to prepare a methodology (which is explained in page 52) to calculate rainfall erosivity in the area. Topographical data was taken from the available map of 1:1200 scale. 
Table 2: Erosion classifications for field survey

\begin{tabular}{|c|l|l|}
\hline Codes & \multicolumn{1}{|c|}{ Coding by Morgan (1995) } & \multicolumn{1}{c|}{ Present Study (Field Survey) } \\
\hline 1 & $\begin{array}{l}\text { No apparent or slight erosion. } \\
\text { Moderate erosion: moderate loss of topsoil } \\
\text { generally and/or marked dissection by } \\
\text { run-off channels or gullies. } \\
3\end{array}$ & $\begin{array}{l}\text { No erosion is visible. } \\
\text { No gully formation or no exposure of plant } \\
\text { geots. Soil loss is less than } 5 \mathrm{~cm} \text { in depth. } \\
\text { generally and/or marked dissection by } \\
\text { run-off channels or gullies. } \\
\text { Very severe erosion: complete truncation of } \\
\text { the soil profile and exposure of the subsoil } \\
\text { and/or deep and intricate dissection by } \\
\text { run-off channels or gullies. }\end{array}$ \\
\hline
\end{tabular}

\section{Model development}

A soil erosion model was prepared adopting the concept of USLE with the help of facilities given by the GIS Arc/ Info and Arc/ View packages. The collected data were logically organized into sets of maps such as rainfall, topography and landuse, since the area has only one soil type and the conservation method has a relationship with the landuse in the area. All the maps are digitised using a digitizing table and transferred into a common coordinate system using ArcInfo software. Once all the maps are in a common coordinate system, attributes are associated with the features. After preparation of three maps using ArcInfo it was taken to the ArcView for preparation of the model.

The model was prepared by adopting the concept of USLE. The USLE has been developed to predict long-term average soil losses due to runoff from small fields under specified cropping and management systems and is expressed as:

$$
A=R K L S C P
$$

Where $A$ is the average annual soil loss, $R$ is the rainfall erosivity, $\mathrm{K}$ is the soil erodibility, $\mathrm{L} \& \mathrm{~S}$ are slope length and slope steepness factors, $C$ is the cover management factor and $P$ is the conservation practice factor. It predicts the longterm average annual rate of erosion on a field slope based on rainfall pattern, soil type, topography, crop system and management practices in spatial extent. Three linear regression relationships were created for the three rainfall stations within the area, to calculate monthly rainfall in the area with the Ratmalana rain gauge station. This is shown in Table 3.
Table 3: Regression Equations relating monthly rainfall of the area with rainfall at Ratmalana

\begin{tabular}{|c|c|c|}
\hline Station & Regression Equation & $\mathbf{R}^{2}$ \\
\hline Station 1 & $\mathrm{St}=1.194 \mathrm{R}-13.189$ & 0.957 \\
Station 2 & $\mathrm{SSt}=1.181 \mathrm{R}-15.223$ & 0.959 \\
Station 3 & $\mathrm{SSt}=1.468 \mathrm{R}-12.740$ & 0.957 \\
\hline
\end{tabular}

Where $S t$ is the rainfall value in each station, $R$ is the rainfall value at Ratmalana rain gauge station and $R^{2}$ is correlation coefficient. Thiessen polygons were drawn to find out the rainfall distribution in the area. Rainfall intensity during the last twenty years at Ratmalana rain gauge station were obtained to calculate the rainfall erosivity using KE $>25$ index. Kinetic energy (KE) estimation of each and every storm involves a tedious task. Hence Hudson (1971) was used to calculate kinetic energy for each duration of a storm, using intensity values of the rain.

$K E=29.8-127.5 / I$

Where, KE is Kinetic Energy in Joules per square meter per mm of rain and I is the Rainfall Intensity in $\mathrm{mm}$ per hour. The sum of KE resulting from a rainfall having an intensity greater than $25 \mathrm{~mm}$ per hour was obtained as the KE $>25$ index. Annual total of erosivity was added in order to calculate the Annual Erosivity (AE) for the area.

The statistical corelation between KE $>25$ index and seasonal rainfall was found with a regression analysis of:

$M S E=1.888 M S R-855.1$

Where, $\mathrm{KE}$ is Kinetic Energy in Joules per square meter per mm of rain, MSE is Mean Seasonal Erosivity and MSR is Mean Seasonal Rainfall. 
Corelation coefficient was found out as $\mathbf{0 . 8 4}$. Using the above equation Seasonal Rainfall Erosivity values are calculated and given in Table 4.

Table 4: Rainfall erosivity within the area

\begin{tabular}{|c|c|}
\hline Rainfall Station & Erodibility (t/ha/yr) \\
\hline Station 1 & 295.39 \\
Station 2 & 289.82 \\
Station 3 & 284.11 \\
\hline
\end{tabular}

Soil erodibility value for Red Yellow Podzolic was taken as 0.22 from Joshua (1977), which is given as soil erodibility values for the Sri Lankan soils. The Slope Class Map was prepared using the contour map. Slope Polygons were prepared as small as possible within two contour lines to minimize the problems arising during overlaying the maps, since slope length is a polygon specific attribute. Map length corresponding to each slope class was calculated and slope length of each polygon in ArcView software was taken by measuring the perpendicular distance between two contours within each polygon. Slope class classification was done using that slope length of each polygon. Slope steepness and slope length factors for the average slope angle of each slope class were calculated using the method mentioned in the USLE (Table 4). Slope length factor is,

$L=\left[\frac{1}{72.6}\right]^{m}$

Where 1 is field slope length and $m$ is equal to 0.3 for slopes less than $5 \%, 0.6$ for slopes greater than $10 \%$ and 0.5 for the average slopes. And slope steepness factor is,

$S=\left[\frac{0.43+0.3 S_{0}+0.043 S_{0}^{2}}{6.613}\right]$

Table 5: Land slopes and extent of the area

\begin{tabular}{|l|c|c|c|}
\hline \multicolumn{1}{|c|}{ Slope Class } & Slope Angle (Deg.) & Slope Length Factor (L) & Slope Steepness Factor (S) \\
\hline 1. Gentle sloping & $0-2$ & 1.147 & 0.164 \\
2. Moderate sloping & $2-4$ & 0.825 & 0.482 \\
3. Strongly sloping & $4-7$ & 0.537 & 1.105 \\
4. Very strongly sloping & $7-14$ & 0.322 & 3.139 \\
5. Steep & $14-20$ & 0.242 & 7.530 \\
6. Very steep & $>20$ & 0.151 & 49.654 \\
\hline
\end{tabular}

Where $S_{0}$ is slope gradient as a percentage. Slope classes since slope length of this slope class was large compared to the other slopes. Polygons in the slope layer should be prepared as small as possible to minimize the problems arising during overlaying. Intermediate contours were drawn at these locations and slope length and steepness for those classes were calculated.

Crop management factors $(C)$ were selected from the literature considering suitability of those factors to the area. Conservation practices used in the area were identified during the field data collection with the knowledge of practices used in Sri Lanka. Conservation practice factor $(P)$ has a relationship with the method of land management such as contouring, terracing etc. used in the area. Conservation practices of land use could be easily corelated with land cover; the $P$ factor values for each conservation method were taken from the literature. $C$ and $P$ values are given in Table 6.

Erosion in the roads and buildings are zero because the road surfaces are paved and buildings have good drainage facilities. When preparing the model, roads and building were taken off from the final map.

The final map containing all the details of rainfall, soil, topography and landuse was prepared using "Geoprocessing" wizard in the ArcView software. The final model was developed by taking weighted average of RKCP (factors in the USLE) in the polygons within each slope class polygons, since slope class is polygón specific.

\section{Model calibration and verification}

The calculated and actual erosion class polygons indicate that some polygons in the 'garden' and part of the 'forest area' were not matching properly. Observed erosion levels and the calculated erosion levels are shown in figure 1 class one was further classified into three slope 
Table 6: $\mathrm{C}$ and $\mathrm{P}$ factors for various landuses in the area

\begin{tabular}{|l|l|c|}
\hline Land Cover & C factor & P factor \\
\hline 1. Forest & 0.001 & 1.0 \\
2. Scrub Cover & 0.01 & 1.0 \\
3. Garden & 0.09 & 0.5 \\
4. Bare space & 1.0 & 1.0 \\
5. Grass Land & 0.012 & 0.14 \\
\hline
\end{tabular}

and figure 2. Therefore, optimisation of minimum error was done during the model calibration and verification process. A trial and error methodology was used for computed classifications for soil erosion to get the best fit with the field collected data. Field collected data was classified numerically into four erosion classes as described in the Table 2. Thus, computed erosion values should be classified into four erosion classes. For that, randomly selected 100 polygons were used for the calibration and another 100 polygons were used for verification. The four erosion class classification schemes were selected using the following statistics and trial and error methodology. The erosion values ranged from 0 to 35.215 tons $/ \mathrm{ha} / \mathrm{yr}$. The mean value of soil erosion of 4353 polygons was 0.9659 tons/ha/yr and the standard deviation was 2.4056. A weighting scheme was selected during the optimization process as $1,5,25$, and 35 tons/ha/ $\mathrm{yr}$ and were assigned to no apparent erosion, moderate erosion, severe erosion and very severe erosion respectively. The mean Ratio of Absolute Error (MRAE) was used as the objective function. Mean Ratio of Absolute Error (MRAE):

\section{$M R A E=(1 / n) \sum\left[\left(E_{0}-E\right) / E_{0}\right]$}

Where $\mathrm{E}, \mathrm{o}, \mathrm{c}, \mathrm{n}$ are for erosion level as, observed, calculated and for number of samples respectively, and were used as the objective function for calibration and verification of the model.

Modeled values were perfectly matched with the actual conditions when those data were classified as $0-1,1-14,14-25,>25$ tons/ha/yr. Optimisation provided the best matching with a minimum calibration MRAE of 0.1698 and verification showed 0.1614 . Thus USLE can be used for this area by taking average annual soil loss of $0-1$ tons/ha/yr as no apparent erosion, 114 tons/ha/yr as moderate erosion, 14-25 tons/ $\mathrm{ha} / \mathrm{yr}$ as severe erosion and $>25$ tons/ha/yr as very severe erosion. . The calculated and actual erosion class polygons indicate some polygons in the garden and part of the forest area were not matching properly because some areas in the garden do not have surface cover like other 'garden' areas and some 'forest areas' do not have proper under cover and litter layer when compared to other forest areas. This can be overcome by considering the percentage canopy cover and surface soil cover when selecting Cfactor for various land uses.

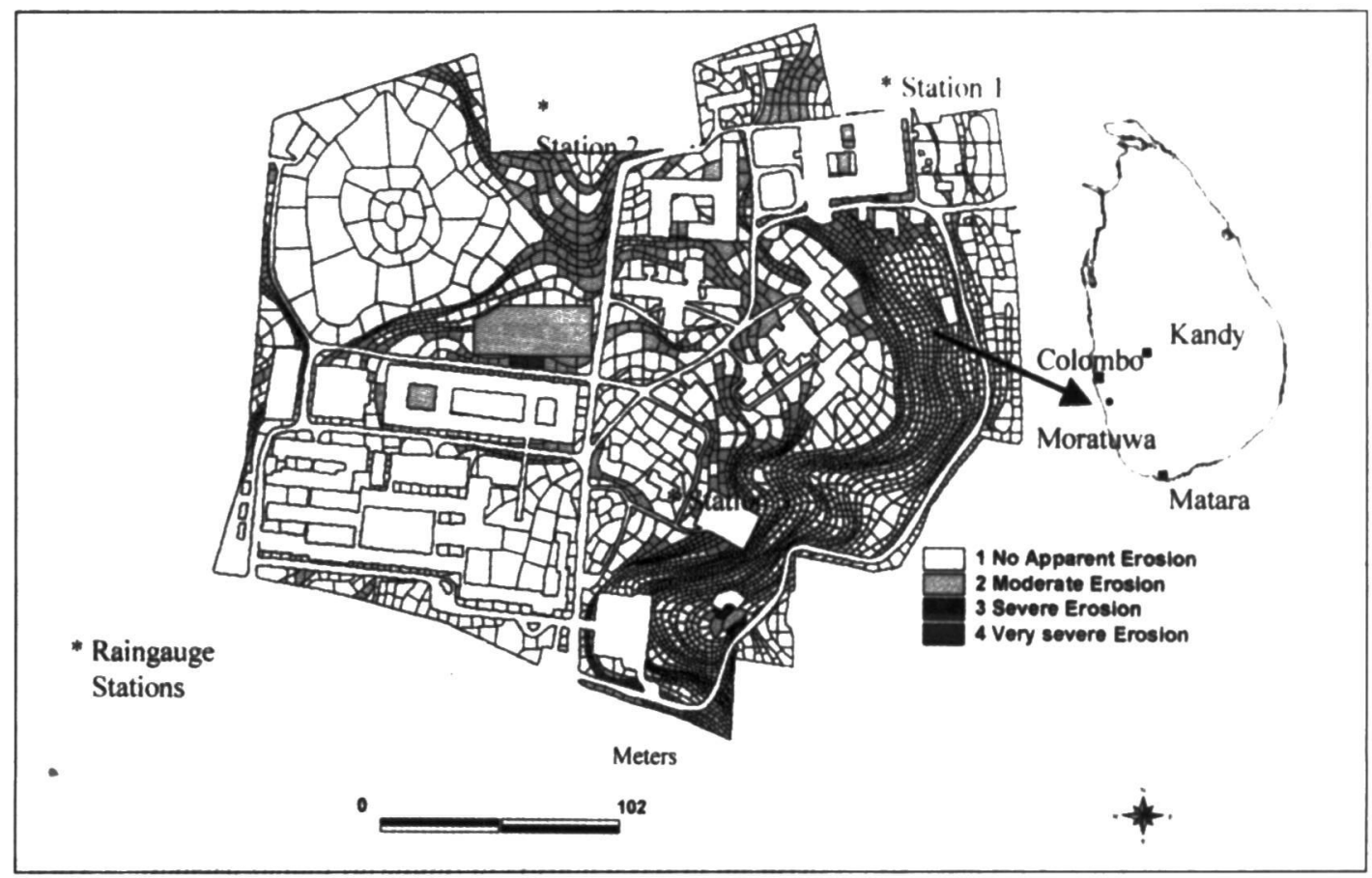

Figure 2: Modeled spatial variations of erosion levels in the area. 


\section{Results and discussion}

1. Soil erosion model validated for the field, based on USLE, showed an erosion classification scheme and these values can be used to identify critical erosion zones for similar areas since all the parameters, except crop management factors and conservation practice factors, were extracted from the area. Therefore, if the model is used for a similar area without changing those factors, annual soil erosion values for each erosion class are, 0-1 tons/ $\mathrm{ha} / \mathrm{yr}$ no apparent erosion, 1-14 tons/ha/yr moderate erosion, 14-25 tons/ha/yr severe erosion and $>\mathbf{2 5}$ tons/ha/yr very severe erosion.

2. The study identified a quantification scheme for pre-coding of parameters, which is a very important aspect of field data collection. Such a quantification scheme has been used in most of similar researches but preparation of the most suitable quantification scheme, relevant to a particular area, offers correct and easy recording ability of the parameters used for the calculations.

3. The model gives incorrect results in the area which has flat terrain. But the land use is considered as bare land. Reason for this problem is that the slope classes represent a range of slopes and only the average value has been taken for calculations. If the area is flat, input value in the model does not indicate that.

4. When the area is not having enough rainfall data or rain gauge stations, rainfall data can be found out easily by regression analysis comparing collected rainfall data in a short period of time in the specified area with that of the data taken from the nearest rain gauge station.

5. The study area is small compared to other research carried out in this field of study. Thus the data collection can be done very accurately by field surveys within a short period of time. If the area is large the most common method of data collection is Remote Sensing but these data should be rechecked using field surveys.

\section{Conclusion}

1. USLE can be successfully used to develop a soil erosion model using GIS for the study area with an MRAE for calibration of 0.1882 and for verification of 0.185 . This model can also be used on similar areas but more consideration should be given when selecting $C$ factors and handling area specific attributes.

2. Crop management factors for this research were selected using average canopy cover within each land use. But the best results can be obtained by dividing the area considering the percentage canopy cover and surface cover.

\section{References}

1 F.A.O Conservation Guide, 1987. Guideline for Economic Appraisal of watershed Management Projects. F.A.O. Rome.

2 Joshua W.D. 1977. Soil Erosive Power of Rainfall in the Different Climatic Zones of Sri Lanka, In Erosion and Solid Matter Transport in Inland Waters, Proceedings of Symposium. Publ. No.122. Paris: IAHSAISH.

3 Karunatilaka G.R.N. and Wijesekera N.T.S. 2001.Key Issues and Reccomendation Related to Field Data Collection in Soil Erosion Assessment Using GIS, Thirteenth Annual Congress, Postgraduate Institute of Agriculture, University of Peradeniya, Sri Lanka.

4 Moormann F. R. and Panabokke (1961). Soils of Ceylon, Tropical Agriculturist, vol. CXVII

5 Morgan R.P.C. 1995. Soil Erosion and Conservation, Longman Group Limited, England. 